\title{
Importance of Circ0009910 in colorectal cancer pathogenesis as a possible regulator of miR-145 and PEAK1
}

Sepideh Kadkhoda ${ }^{1}$, Reza Taslimi ${ }^{2}$, Farshid Noorbakhsh ${ }^{3}$, Farzaneh Darbeheshti ${ }^{1,4}$, Javad Tavakkoly Bazzaz ${ }^{1}$ Soudeh Ghafouri-Fard ${ }^{5^{*}}$ and Abbas Shakoori ${ }^{1,6^{*}}$

\begin{abstract}
Introduction: Colorectal cancer (CRC) is one of the most frequent neoplasms in the world. Based on the emerging role of noncoding RNAs, particularly circular RNAs in pathogenesis of cancers, we designed this study to inspect the expression levels of a circ0009910-mediated regulatory pathway in colorectal cancer.

Methods: After bioinformatics analyses and construction of putative circ0009910/ miR-145-5p/PEAK1 pathway, the expression levels of these components were evaluated in 50 CRC tissues and adjacent specimens by quantitative real-time PCR. Moreover, we appraised the correlation coefficients between these transcripts and calculated the correlation between circ0009910 expression levels with clinicopathological features of patients.

Results: Circ0009910 and PEAK1 were significantly upregulated, while miR-145-5p was decreased in CRC samples compared with adjacent tissues ( $p<0.05$ ). Moreover, statistically significant correlations were observed between expression levels of circ0009910, miR-145-5p, and PEAK1. We also reported considerable correlations between circ0009910 expression and clinicopathological parameters including sex and perineural invasion. Finally, ROC curve analysis showed circ0009910 level as a discriminative biomarker for CRC.

Conclusion: For the first time, we could introduce circ0009910 as an important biomarker in CRC. Collectively, this investigation helped us to identify a newly diagnosed pathway in CRC that can be a potential axis for designing effective drugs for treatment of CRC patients.
\end{abstract}

Keywords: Colorectal cancer, Circ0009910, miR-145-5p, PEAK1, Non-coding RNA

\section{Introduction}

Among all malignancies, colorectal cancer (CRC) is the third most frequent neoplasm and it ranks fourth in terms of cancer deaths [1]. Australia and New Zealand have the highest rates of CRC [2]. Unfortunately, the prevalence of this disease has increased in most parts of the world with the change of people's lifestyle,

\footnotetext{
* Correspondence: s.ghafourifard@sbmu.ac.ir; shakooria@sina.tums.ac.ir ${ }^{5}$ Department of Medical Genetics, Shahid Beheshti University of Medical Sciences, Tehran, Iran

'Department of Medical Genetics, School of Medicine, Tehran University of Medical Sciences, Tehran, Iran

Full list of author information is available at the end of the article
}

particularly inappropriate eating habits, obesity, adopting a machine life, and increasing consumption of tobacco and alcohol [3]. A previous systematic review and metaanalysis has shown that incidence rate of CRC has raised in Iran possibly as a result of increasing personal and environmental risk factors in addition to enhancement of cancer registries and availability of health services [4]. Age-standardized incidence values in Iran have been reported to be 8.16 and 6.17 for men and women, respectively [4]. CRC often occurs in a sporadic form, but a percentage of cases are inherited or due to inflammatory bowel disease [5]. This malignancy is heterogeneous and

C C The Author(s). 2021 Open Access This article is licensed under a Creative Commons Attribution 4.0 International License, which permits use, sharing, adaptation, distribution and reproduction in any medium or format, as long as you give appropriate credit to the original author(s) and the source, provide a link to the Creative Commons licence, and indicate if changes were made. The images or other third party material in this article are included in the article's Creative Commons licence, unless indicated otherwise in a credit line to the material. If material is not included in the article's Creative Commons licence and your intended use is not permitted by statutory regulation or exceeds the permitted use, you will need to obtain permission directly from the copyright holder. To view a copy of this licence, visit http://creativecommons.org/licenses/by/4.0/. The Creative Commons Public Domain Dedication waiver (http://creativecommons.org/publicdomain/zero/1.0/) applies to the data made available in this article, unless otherwise stated in a credit line to the data. 
genetic and environmental factors partake in this disease [6]. Despite recent advances in the diagnosis and treatment, the prognosis of CRC is still poor because of late detection, metastasis to distant organs, and disease recurrence. From a genetic standpoint, the discovery of potentially effective biomarkers contributing in CRC pathogenesis can contribute in faster detection of at-risk individuals and increasing of their life expectancy [7]. A recent study has shown the importance of long noncoding RNAs in the pathogenesis of CRC and introduced a prognosis model for CRC based on expression profile of six of these transcripts [8]. Another study has designed a prognostic predictor for CRC through comprehensive assessment of alternatively spliced transcripts [9]. Other bioinformatics methods have identified a 12gene signature that can predict prognosis of CRC with high efficiency [10]. Moreover, combined assessment of expression of RNA-binding proteins in CRC samples has led to identification prediction models for this malignancy [11]. Among genes which are associated with CRC prognosis are $\mathrm{Na}+/ \mathrm{Ca} 2+$ exchangers [12], ferroptosis-related genes [13], and those participating in chemokine signaling and cytokine-cytokine receptor interactions [14].

Circular RNAs as emerging group of stable noncoding RNAs with circular configuration play significant roles in the pathogenesis of various disorders, particularly cancers [15]. So, they have attracted the attention of many researchers in the field of biomarker discovery. Yet, research in this area is still in its infancy [16]. They are formed through construction of a closed loop between two ends of their host genes. They can act as molecular sponges for miRNAs [17]. Although they were initially thought as error products of splicing, their importance in diverse cellular processes was gradually realized [18]. For instance, circ_0055625 has been found to participate in the pathogenesis of $\mathrm{CRC}$ and response to radiotherapy through influencing miR-338-3p/MSI1 axis [19]. miRNAs as another non-coding RNAs play important roles in genes expression modification. These small RNAs act as oncogene or tumor suppressors and regulate expression of genes through binding to 3' untranslated regions of target genes [20]. It is estimated that expression of $60 \%$ of genes is influenced by miRNAs [21, $22]$. Based on the bioinformatics analysis from NCBI Gene Expression Omnibus (GEO) and different databases, we predicted the presence of regulatory axis, namely, circ0009910/miR-145-5p/PEAK1 axis. The length of exonic circ0009910 is 315 base pairs that are produced from MFN2 located on chromosome 1 as the host gene. PEAK1 (also known as KIAA2002) is located on 15q24.3. The protein has a molecular mass of 193106 $\mathrm{Da}$, is a member of NFK3 family, and acts as a tyrosine kinase. This kinase is functionally associated with actin protein and thereupon, has a role in cell connections and migrations [23].

In the recent studies, the role of circ0009910 as an oncogene has been discovered in a few cancers [24]. Yet, it has not been studied in CRC. So, we designed this study to quantify the expression level of circ0009910, miR-145-5p, and PEAK1 in CRC tumors compared to adjacent tissues. Also, the relationship between expression of these genes and the clinical parameters of the patients such as age, gender, tumor diameter, stage, grade, and other features was explored.

\section{Methods}

\section{Bioinformatics analysis}

In a recent study, we have analyzed GPL19978 platform from GEO microarray dataset (GSE126095) and detected 37 differentially expressed circRNAs between cancer and non-cancer tissues using a cut-off point of adjusted $P$ value $<0.05$ and log fold change $\geq|3|$ (supplementary table 1) [25].

In the current study, the exonic circ0009910 (circ100053) as a differentially expressed (DE) circular RNA between colorectal tumors and adjacent tissues was selected $(\log \mathrm{Fc}=3.03281$ and adj $p$ value $=2.06 \mathrm{E}$ -05). Then, GSE128449 (platform GPL14767) was analyzed to determine DEmiRNAs between colorectal tumors and adjacent tissues. In this step, DEmiRNAs with adjusted $P$ value $<0.05$ and log fold change $\geq|3|$ were picked out.

Using Circular RNA Interactome database, it was found that circ0009910 has connection site for $17 \mathrm{miR}$ NAs (supplementary table 2). Through investigating this database and GSE128449, miR-145-5p as a DEmiRNA and target of this circular RNA was selected $(\log \mathrm{Fc}=$ -4.14554 and adj $p$ value $=4.10 \mathrm{E}-05$ ). For the selection of DEmRNAs between colorectal tumors and adjacent tissues, GSE41657 (platform GPL6480) was analyzed and DEmRNAs that had the criteria of log fold change $\geq|2|$ and adjusted $P$ value $<0.05$ were considered.

PEAK1 gene (pseudopodium enriched atypical kinase 1) was diagnosed as a target of miR-145-5p through analysis of GSE41657 and assessment of TargetScan and miRmap databases $(\log \mathrm{Fc}=2.313187$ and adj $p$ value $=5.12 \mathrm{E}-05)$. Then, circRNA/miRNA/mRNA pathway was organized for subsequent studies. We hypothesized that circ0009910 regulates PEAK1 through sponging miR-145-5p.

The interaction site between circ0009910 and miR$145-5 \mathrm{p}$ and also three interaction sites between miR145-5p and PEAK1 are illustrated in Figs. $1 \mathrm{a}$ and b, respectively.

\section{Tissue samples collection}

First, fifty paired specimen of CRC tissues and adjacent corresponding tissues were purchased from tumor bank 
a

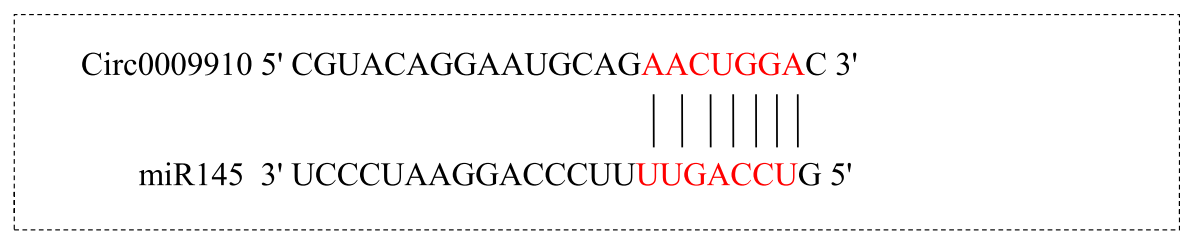

b

PEAK1 5' UAGGACCUUUGAAUUUGUUCAUCAACUGGAAAGAAAUCC 3'

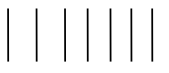

MiR145 3' UCCCUAAGGACCCUUUUGACCUG 5'

PEAK1 5' CAUUCUUGGAGAGGGGUGAGACAAACUGGACUUGCUGGG 3'

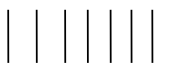

miR145 3' UCCCUAAGGACCCUUUUGACCUG 5'

PEAK1 5' CACCAACCCCUAGGCUGAGCUAGAACUGGAAGCCAGGAA 3'

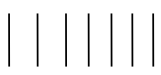

miR145 3' UCCCUAAGGACCCUUUUGACCUG 5'

Fig. 1 a One interaction site between circ0009910 and miR-145-5p according to Circular RNA Interactome database. b Three interaction sites between miR-145-5p and PEAK1 according to miRmap database

of Imam Khomeini Hospital (Tehran, Iran). The Ethical Committee of Tehran University of Medical Sciences approved this study (Ethical code: IR.TUMS.MEDICINE.REC.1399.590). These samples were taken from people of Iranian descent and none of them received chemotherapy and radiotherapy before surgery. Moreover, 10 normal colorectal tissues were obtained. The written consent form was signed by these individuals. The clinicopathological information such as age, gender, tumor size, stage and grade of tumors, invasion status, clinical metastasis, smoking history, and family history of $\mathrm{CRC}$ were also obtained. All tissues were kept at $-70^{\circ} \mathrm{C}$.

\section{RNA extraction and CDNA synthesis}

The Riboex (geneall, Korea) was used to extract total RNA from tumors, adjacent tissues, and normal tissues following the instructions of the solution. The quantity of extracted RNAs was assessed by the Nanodrop 2000C (Thermo Scientific, USA). RNA was also subjected to electrophoresis on $1.5 \%$ agarose gel for RNA quality assessment. Then, cDNA was produced from $50 \mu \mathrm{g}$ of RNAs by cDNA synthesis kit (Yekta Tajhiz Azma, Iran).
The specific stem loop RT primer for miR-145-5p and snRNA U6 was added to the reaction mixture. The resulting mixture for production of cDNA was subjected to the following temperature conditions: $15 \mathrm{~min}$ at 37 ${ }^{\circ} \mathrm{C}, 60 \mathrm{~min}$ at $42{ }^{\circ} \mathrm{C}$ for, and then $5 \mathrm{~min}$ at $70{ }^{\circ} \mathrm{C}$.

\section{Quantitative real-time PCR}

The suitable primers designed with help of Circular RNA Interactome, Primer_Blast and Gene Runner software. Moreover, the circPrimer 1.2 software was used to assess the specificity of circRNA primers. The sequences of primers are displayed in Table 1.

Relative expressions of circRNA0009910, miR-145-5p, and PEAK1 were measured in all tissues using RealQ Plus $2 \times$ Master Mix Green low Rox (Ampliqon, Denmark). Reactions were performed in the LightCycler 96 Real-Time PCR System (Roche, Germany). All of the qPCR reactions were performed in duplicate. $B 2 M$ was used as the reference gene for circRNA0009910 and PEAK1. snRNA U6 was selected as the reference gene for miR-145-5p. Thermal cycling conditions for miR-145-5P and PEAK1 consisted of preincubation at 95 ${ }^{\circ} \mathrm{C}$ for $900 \mathrm{~s}$ followed by amplification in 40 cycles at $95{ }^{\circ} \mathrm{C}$ 
Table 1 Sequences of primers

\begin{tabular}{lll}
\hline Primer name & Primer type & Sequence $\mathbf{( 5}^{\prime} \rightarrow \mathbf{3}^{\prime} \mathbf{)}$ \\
\hline circ0009910 & Forward & TTGGCCGCGCAATGTCC \\
miR-145-5p & Divergent reverse & GCATTCACCTCAGCCATGTGTC \\
& Stem loop RT & GTCGTATCCAGTGCAGGGTCCGAGGTATTCGCACTGGATACGACAGGGAT \\
& Forward & GGCTTAGTCCAGTTTCCCAG \\
PEAK1 & Universal reverse & GTGCAGGGTCCGAGGT \\
& Forward & CTATGGACCCGAACCCTTGTAG \\
SnRNA U6 & Reverse & GGTTGGAAGCATTGGGTG \\
& Stem loop RT & AACGCTTCACGAATTGCGT \\
& Forward & CTCGCTTCGGCAGCACA \\
B2M & Reverse & AACGCTTCACGAATTGCGT \\
& Forward & CCACTGAAAAAGATGAGTATGCCT \\
& Reverse & CCAATCCAAATGCGGCATCTTCA \\
\hline
\end{tabular}

for $15 \mathrm{~s}$ and $60{ }^{\circ} \mathrm{C}$ for $45 \mathrm{~s}$. The suitable annealing temperature for circ 0009910 was $59{ }^{\circ} \mathrm{C}$. The PCR products were run on $2 \%$ agarose gel. The back splice junction of circ0009910 was verified by Sanger sequencing. For determination of the fold change of the genes, $2^{-\Delta \Delta C T}$ formula was applied. In this study, normal colorectal tissues were used as calibrator for the relative expression analysis.

\section{Statistical analysis}

All statistical analysis in this study was accomplished by the GraphPad Prism 8.0 (GraphPad Software, Inc., San
Diego, CA) software. The relative expression of circ0009910, miR-145-5p, and PEAK1 was evaluated in colorectal tumors and adjacent tissues using the paired sample $t$ test. The correlation of expression of these three genes was measured using Spearman correlation coefficient. Association between expression of circ0009910 and clinicopathological features of patients was calculated by Mann-Whitney and one-way ANOVA tests (Kruskal-Wallis). Also, the receiver operating characteristic (ROC) curve was illustrated by the GraphPad Prism v.8 software. The $p$ value $<0.05$
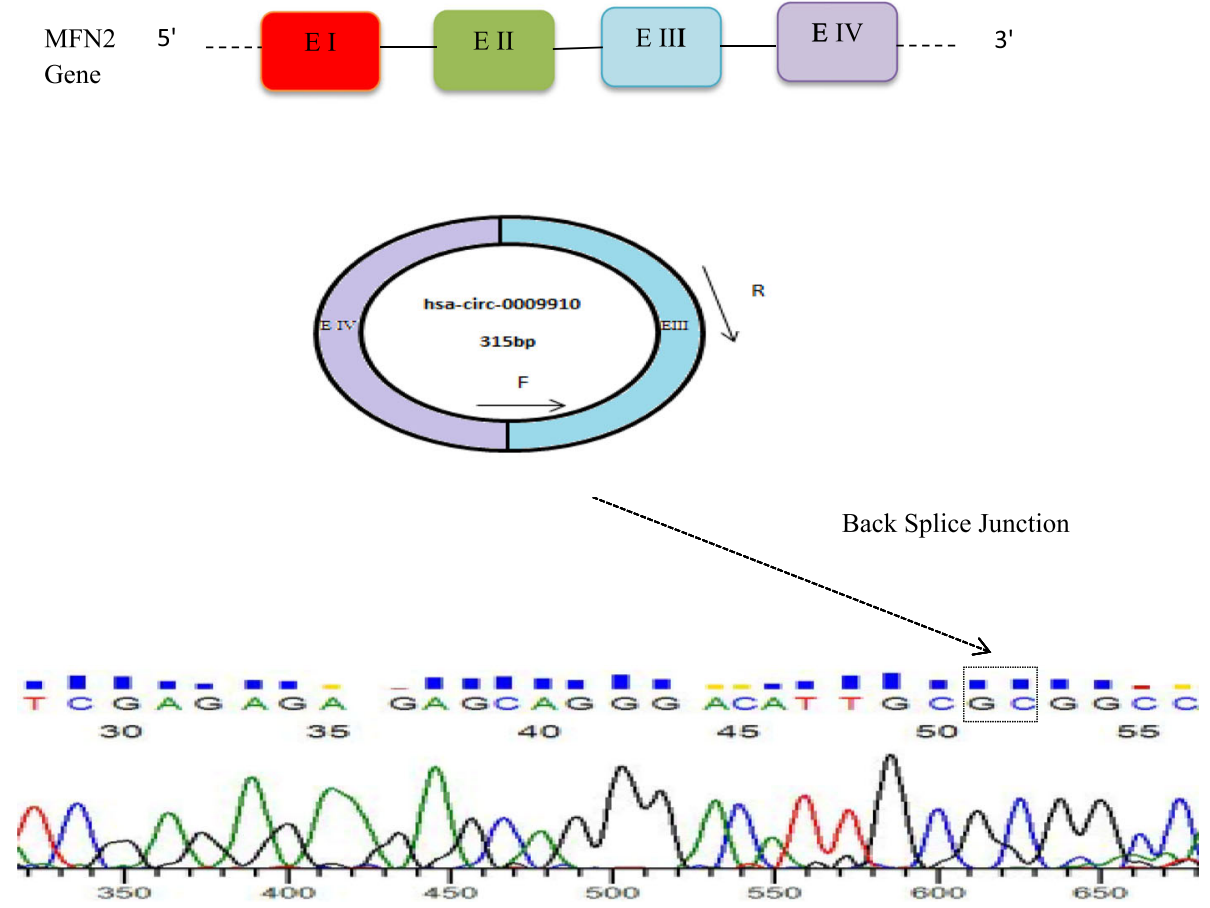

Fig. 2 The schematic image of circ0009910 production from MFN2 gene on chromosome 1. The back-splice intersection location of circ0009910 was verified by Sanger sequencing 
was considered to define the statistical significance in all of measurements.

\section{Results}

Expression analysis of circ0009910, miR-145-5p, and PEAK1

By the Sanger sequencing back splice junction arising from connecting of exon 3 and exon 4 of MFN2 gene as host gene of circ0009910 was verified (Fig. 2).

We found considerable upregulation of circ0009910 in colorectal tumors compared with adjacent tissues ( $P$ value < 0.0001) (Fig. 3a). This finding supported GSE126095 results. Moreover, significant decrease of miR-145-5p ( $P$ value $<0.0001)$ and increase of PEAK1 ( $P$ value $<0.0001)$ levels were observed in colorectal tumors compared with adjacent tissues (Fig. $3 b$ and c).

\section{Correlation analysis between expression levels of} circ0009910, miR-145-5p, and PEAK1

Correlation analysis between expression levels of circ0009910, miR-145-5p, and PEAK1 was accomplished by Spearman correlation coefficient. Results showed negative significant correlation of circ0009910 and miR145-5p ( $r=-0.387$ and $P$ value $<0.0001)$ (Fig. 4a). Also, our study showed that there is a negative considerable correlation between miR-145-5p and PEAK1 $(r=-0.213$ and $P$ value $=0.033)($ Fig. $4 \mathrm{~b})$.

Moreover, positive significant correlation of circ0009910 with PEAK1 was demonstrated $(r=0.649$ and $P$ value $<0.0001$ ) (Fig. 4c).

Thus, according to expression correlations between these two non-coding RNA and their down-stream gene, our hypothesis was proved. Finally, we depicted hierarchical clustering showing expression values (log2 transformed) of circ0009910, miR-145-5p, and PEAK1 in $\mathrm{CRC}$ samples relative to non-cancerous colorectal tissues (Fig. 5).

The importance of circ0009910 as a valuable biomarker in colorectal cancer

We used $2^{\wedge}$-delta $\mathrm{Ct}$ values (Ct Target gene-Ct Normalizer) in adjacent tissues and tumoral tissues, separately. Then, we used these values for making ROC curves. ROC curve analysis verified the possible clinical
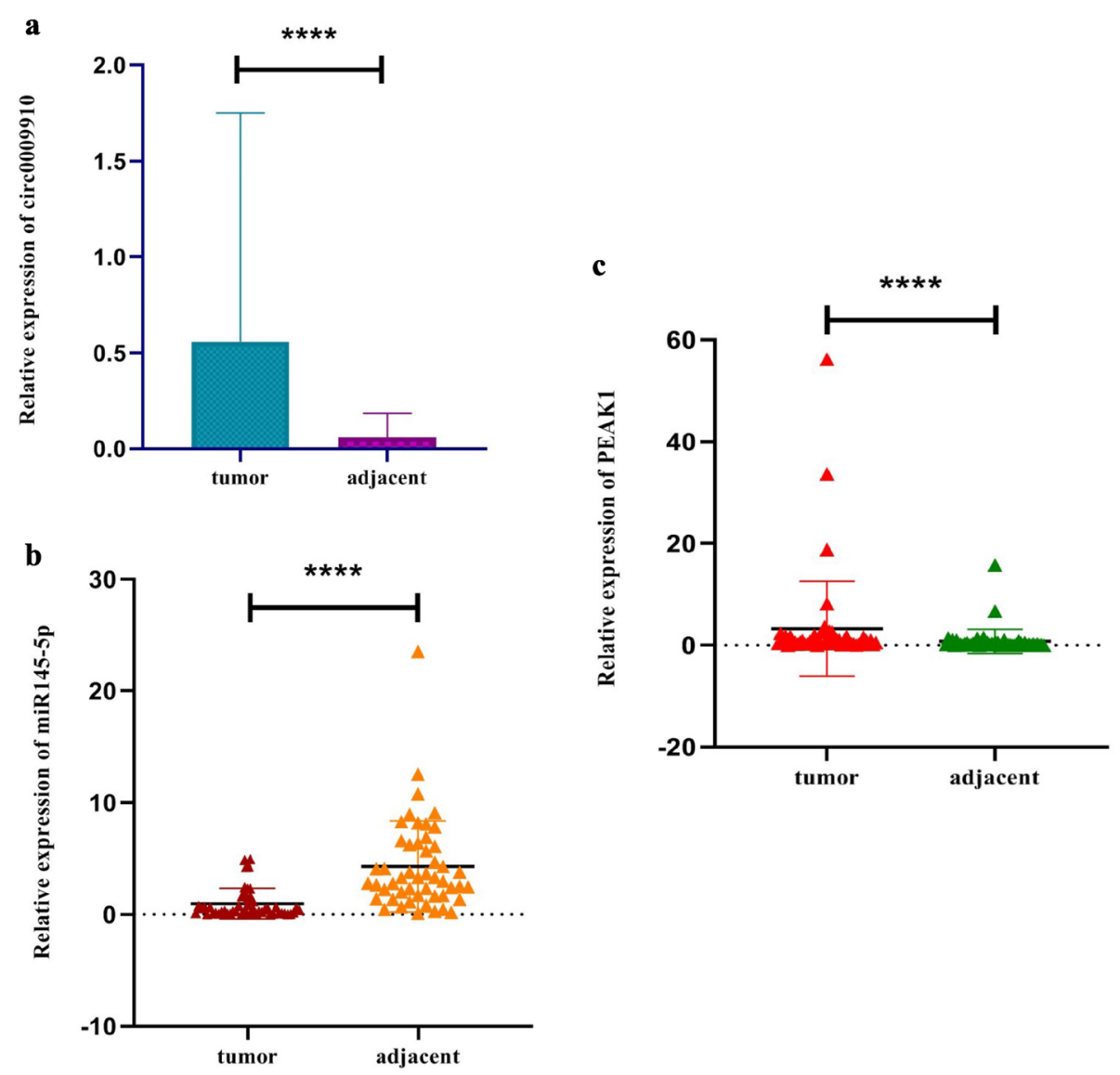

Fig. 3 The relative expression of circ0009910 (a), miR-145-5p (b), and PEAK1 (c) in colorectal cancer relative to adjacent tissues. Asterisks indicate significant difference between two mentioned groups $(P$ value $=<0.0001)$ 
a

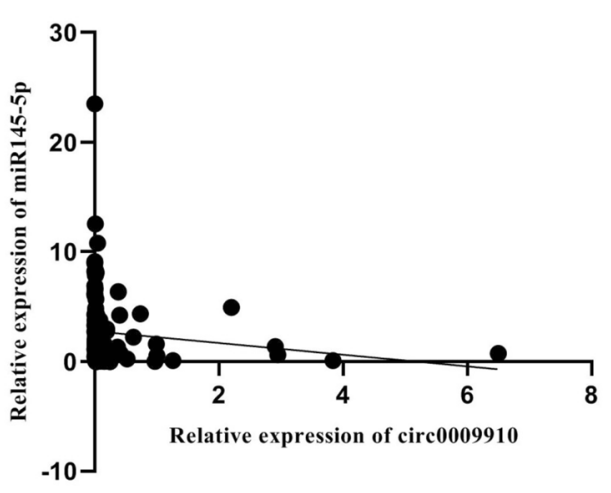

c

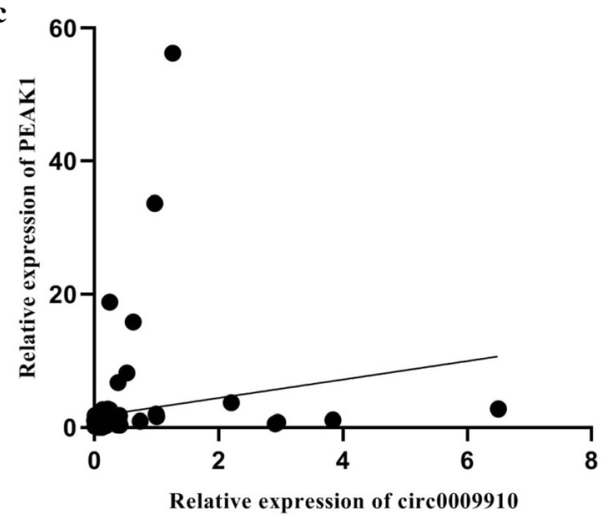

b

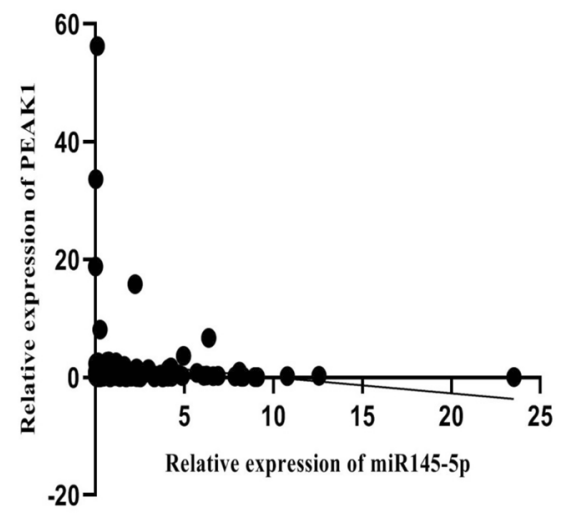

Fig. 4 a The negative association between circ0009910 and miR-145-5p expression in CRC $(r=-0.387, P$ value $<0.0001)$. b The negative association between miR-145-5p and PEAK expression in CRC $(r=-0.213, P$ value $=0.033)$. $\mathbf{c}$ The positive association between circ0009910 and PEAK1 expression in CRC $(r=0.649, P$ value $<0.0001)$

efficiency of circ0009910 in CRC as a distinctive biomarker. This evaluation revealed that circ0009910 can be proposed as a valuable biomarker for CRC (AUC = 0.82 ; $P$ value $<0.0001)$ with $72 \%$ sensitivity and $84 \%$ specificity in the cutoff value $<0.025$ (Fig. 6).

\section{Correlation analysis between expression levels of circ0009910 and clinicopathological features of CRC patients}

The clinicopathological data of patients as age, gender, tumor size, grade and stage and etc., are demonstrated in Table 2. Clinicopathological analyses showed that upregulation of the circ0009910 in colorectal tumors are associated with gender $(P$ value $=0.0108)$ and perineural invasion $(P$ value $=0.0301)$.

\section{Discussion}

Nowadays, the role of noncoding RNAs such as miRNAs, long non-coding RNAs, and circular RNAs has been recognized in the pathogenesis of different diseases including cancer [26]. CRC is one of the most frequent neoplasms in the world and 1.9 million new CRC patients were diagnosed in 2020 [27]. So far, the involvement of a number of circular RNAs including ciRS-7-A [28], circITGA7 [29], PIP5K1A [30], GLIS2 [31], and HIPK3 [32] in the development of colorectal cancer has been identified.

The oncogenic role of circ0009910 has been studied in limited types of tumors, but no studies have been done in CRC. According to Li study in 2019, overexpression of circ0009910 in patients with ovarian cancer has been associated with poor prognosis. In this type of cancer, circ0009910 has been found to target miR-145 and act as a sponge for this miRNA [33]. In hepatocellular carcinoma, circ0009910 has been identified as an oncogenic RNA. This circRNA had negative correlation with miR335-5p and promoted proliferation, invasion, and metastasis of these cells. As ROCK1 expression is influenced by miR-335-5p, circ0009910 can indirectly regulate expression of ROCK1 [34]. In gastric cancer, expression of circ000910 has been associated with advanced stage, undesirable overall survival and higher possibility of metastasis. On the other hand, its inhibition has reduced cell growth and aggressive power of tumor, increased expression of E-cadherin and reduced expression of snail, Ncadherin, and mesenchymal elements [24]. 
$\mathbf{a}$

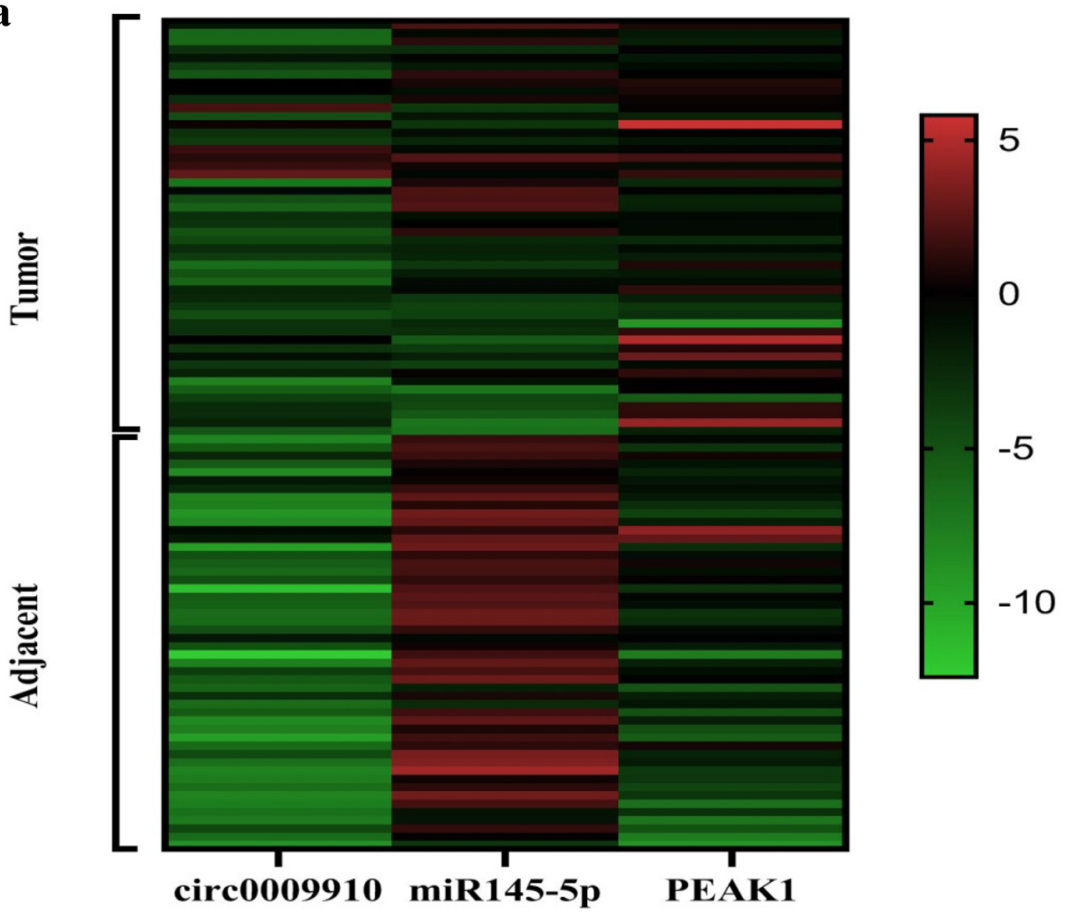

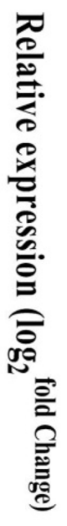

b

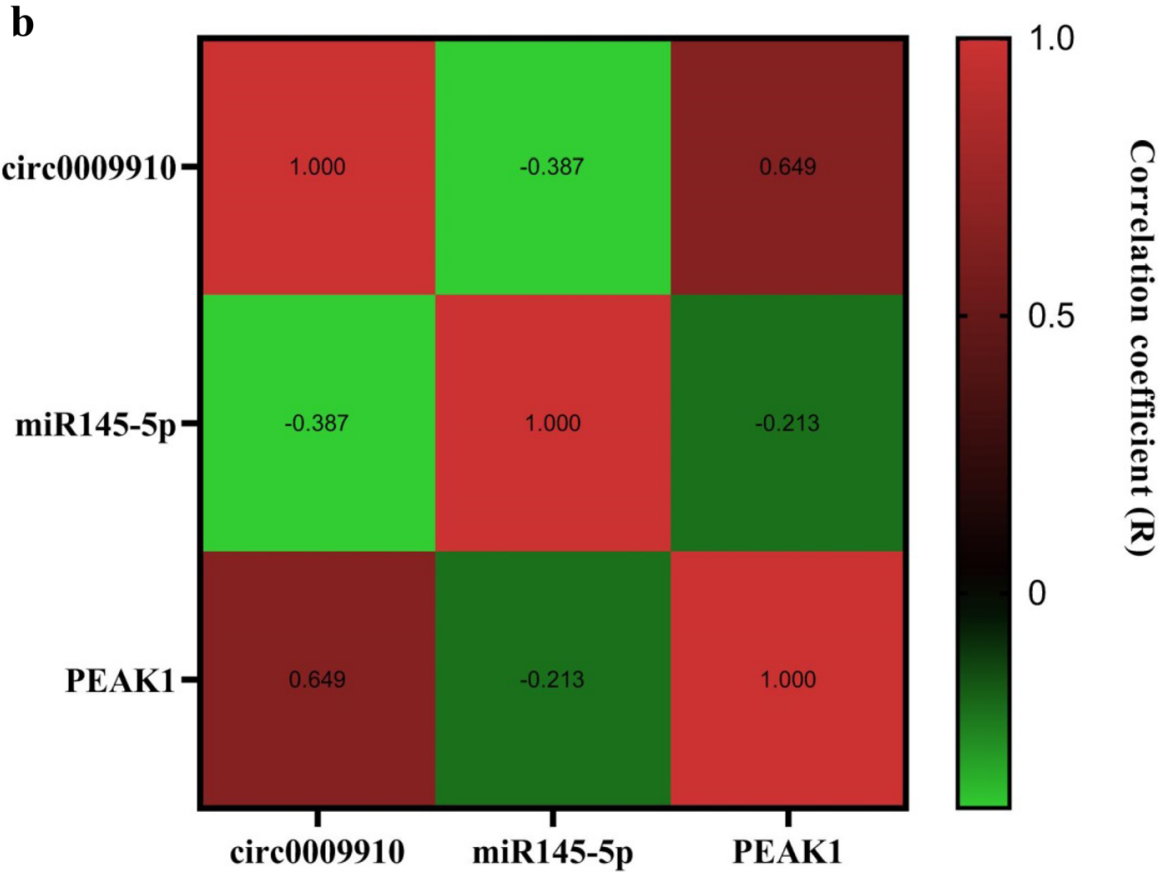

Fig. 5 (a) The grouped graph of expression correlation of circ0009910 (a), miR-145-5p (b), and PEAK1 (c) in colorectal cancer and adjacent tissue as computed by nonparametric Spearman correlation. (b) Hierarchical clustering showing expression values (log2 transformed) of circ0009910, miR-145-5p, and PEAK1 in CRC samples compared with adjacent colorectal tissues. Red strips indicate high relative expression and green strips indicate low relative expression. The rows and columns show samples and transcripts respectively 


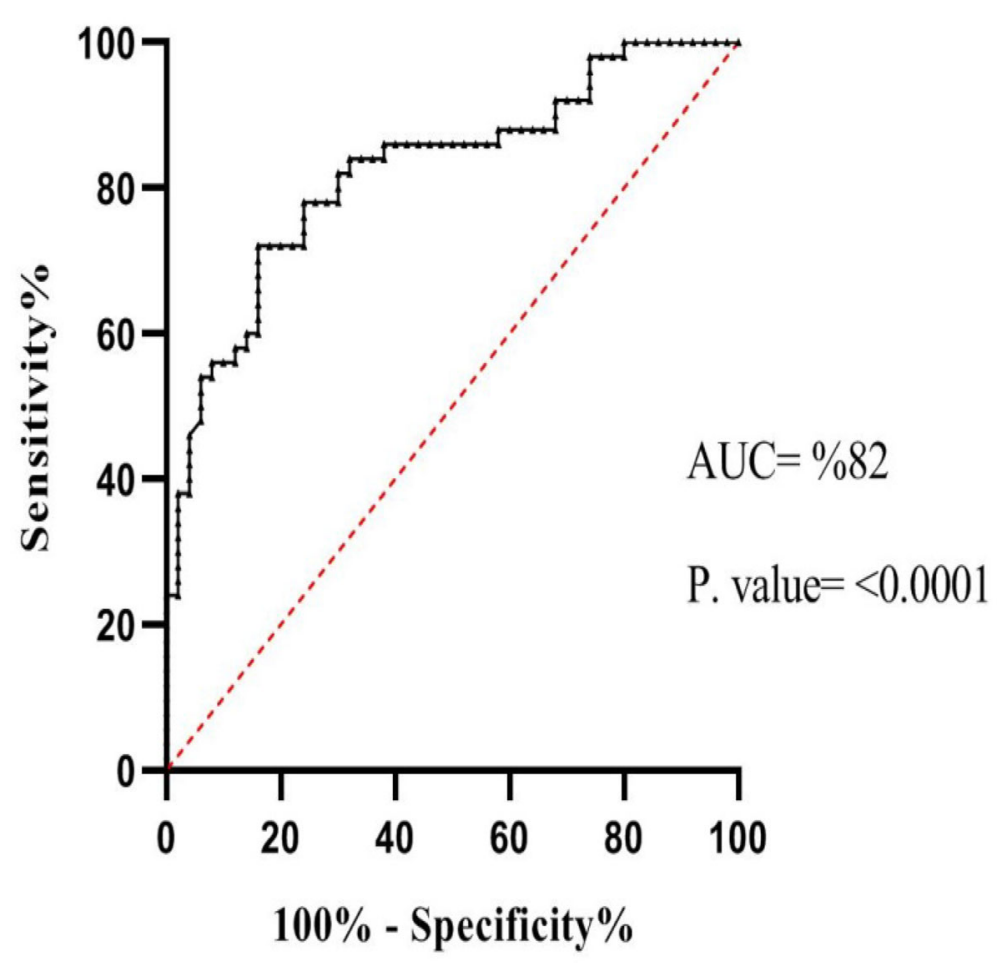

Fig. 6 The receiver operating characteristic (ROC) curve of circ0009910 expression for discrimination of colorectal tumors from adjacent tissues. AUC indicates area under the ROC curve

In patients with CML who developed resistance to imatinib, circ0009910 acts as a sponge for miR34a-5p and activates autophagy mechanism, thus reducing the life expectancy of patients [35]. In AML, upregulation of circ0009910 has been associated with weak prognosis of the patients. Moreover, this non-coding RNA sponges miR20a-5p and inhibits apoptosis [36].

Consistent with this report, Deng et al. have discovered the effects of circ0009910 on miR-449a-IL6R/ $\mathrm{BCL} 2 / \mathrm{BAX}$ pathway regulate cell proliferation, cell immortality, and resistance to cell cycle inhibitors [37]. According to Feng et al.'s investigation, miR-145 is downregulated in colorectal tumor specimens in association with poor clinical outcome. Artificial enhancement of miR-145 expression in colorectal cell lines led to decreasing of cell proliferation, motility, and invasion. In addition, this small non-coding RNA inhibited Fascin-1 [38]. In breast cancer, ZMYND10 via increasing expression of miR-145 and downregulation of NEDD9 suppressed proliferation, migration, and invasion of cells [39].

Negative expression of PEAK1 in gastric tumors and its relationship with tumor grade, invasion, and lymph node metastasis showed the role of this gene in epithelial to mesenchymal transition (EMT) [40]. However, Ding et al. have reported upregulation of PEAK1 in lung cancer and its influence on ERK1/2 and JAK2 signaling as well as expressions of MMP2, MMP9, EMT, and metastasis [41]. In colorectal tumors, two different studies have reported conflicting results about the role of PEAK1 gene. First, authors have reported downregulation of PEAK1 and significant association between its downregulation and larger tumor diameter, poor differentiation, high probability of metastasis, and advanced stage. Moreover, they demonstrated positive correlation between PEAK1 expression and PPP1R12B and its inhibitory effect on Grb2/PI3K/Akt pathway [42]. In another study, authors have reported oncogenic role for PEAK1 in CRC. Moreover, they have demonstrated the role of EGFR/KRas signaling axis and miR-181d on its expression [43].

In this survey, we examined expression of circ0009910/miR-145-5p/PEAK1 axis in fifty pairs of colorectal tumor samples and their adjacent tissues. In this project, we organized a two-stage approach including bioinformatics analysis for organization of a potential hypothetical pathway and then performing laboratory experiments.

The present study provided compelling evidence that circ0009910 is a novel dysregulated circular RNA in 
Table 2 The association between of circ0009910 expression and clinicopathological features of CRC patients. There is significant correlation between circ0009910 level and gender of patients and perineural invasion ( $P$ value $<0.05)$

\begin{tabular}{|c|c|c|c|c|}
\hline Parameters & Subclasses & Number of patients (\%) & Median of circ0009910 expression & $P$ value \\
\hline \multirow[t]{2}{*}{ Gender } & Female & $19(38 \%)$ & 0.03 & 0.0108 \\
\hline & Male & $31(62 \%)$ & 0.14 & \\
\hline \multirow[t]{2}{*}{ Age (years) } & $<50$ & $23(46 \%)$ & 0.14 & 0.0832 \\
\hline & $\geq 50$ & $27(54 \%)$ & 0.08 & \\
\hline \multirow[t]{3}{*}{ Tumor diameter } & $<2$ & $1(2 \%)$ & 0.40 & 0.2504 \\
\hline & $2-5$ & $26(52 \%)$ & 0.27 & \\
\hline & $>5$ & $23(46 \%)$ & 0.88 & \\
\hline \multirow[t]{3}{*}{ Grade } & । & $13(26 \%)$ & 0.66 & 0.4557 \\
\hline & $\|$ & $30(60 \%)$ & 0.62 & \\
\hline & III & $7(14 \%)$ & 0.16 & \\
\hline \multirow[t]{2}{*}{ Lymphatic invasion } & Yes & $39(78 \%)$ & 0.12 & 0.3302 \\
\hline & No & $11(22 \%)$ & 0.04 & \\
\hline \multirow[t]{2}{*}{ Vascular invasion } & Yes & $39(78 \%)$ & 0.12 & 0.3302 \\
\hline & No & $11(22 \%)$ & 0.04 & \\
\hline \multirow[t]{2}{*}{ Perineural invasion } & Yes & $9(18 \%)$ & 0.73 & 0.0301 \\
\hline & No & 41 (82\%) & 0.11 & \\
\hline \multirow[t]{4}{*}{ Clinical stage } & 1 & $1(2 \%)$ & 1.003 & 0.4094 \\
\hline & $\|$ & $24(48 \%)$ & 0.67 & \\
\hline & III & 17 (34\%) & 0.39 & \\
\hline & IV & $8(16 \%)$ & 0.50 & \\
\hline \multirow[t]{2}{*}{ Family history } & Yes & $15(30 \%)$ & 0.14 & 0.8342 \\
\hline & No & $35(70 \%)$ & 0.11 & \\
\hline \multirow[t]{2}{*}{ Smoking } & Yes & $8(16 \%)$ & 0.13 & 0.7065 \\
\hline & No & 42 (84\%) & 0.11 & \\
\hline
\end{tabular}

CRC. Circ0009910 was significantly upregulated in colorectal tumor tissues compared with adjacent tissues. It is worth mentioning that the selection criterion of the expression level changes $>3 \times$ in our study does not necessarily result in identification of genes with critical activity in the pathogenesis of CRC or critical importance over the process of carcinogenesis.

Also, expressions of miR-145-5p and PEAK1 in colorectal tumors compared with adjacent tissues were down- and upregulated, respectively. On the other hand, the significant correlation between circ0009910, miR145-5p, and PEAK1 was observed. ROC curve analysis illustrated that circ0009910 can be as a putative biomarker in CRC. GEO data and bioinformatics analysis along with experimental analysis reinforced the hypothesis that circ0009910 regulates PEAK1 by sponging of miR-145-5p.

\section{Conclusion}

Altogether, our study identified this axis as a potential contributor in the pathogenesis of CRC. Further experiments would help in identification of its role as a therapeutic target in CRC.

\section{Supplementary Information}

The online version contains supplementary material available at https://doi. org/10.1186/s12957-021-02378-0.

Additional file 1: Supplementary Table 1.

Additional file 2: Supplementary Table 2.

Acknowledgements

We thank all patients whose samples were used in this study.

Authors' contributions

SK: experimental studies, visualization, and manuscript preparation; RT: manuscript preparation; FN and JTB: concept and design, FD: statistical analysis; SGF and AS: project administration and manuscript editing. The author(s) read and approved the final manuscript.

Funding

This study was supported by Department of Medical Genetics, Faculty of Medicine, Tehran University of Medical Sciences (TUMS), Tehran, Iran (Grant Number: 45684). The funding body had no role in the design of the study and collection, analysis, and interpretation of data and in writing the manuscript. 


\section{Availability of data and materials}

The datasets supporting the conclusions of this article are available in https://www.ncbi.nlm.nih.gov/geo/. The data supporting the conclusions of this article are also included within supplementary tables 1 and 2 .

\section{Declarations}

\section{Ethics approval and consent to participate}

The study protocol was approved by ethical committee of Tehran University of Medical Sciences (Ethical code: IR.TUMS.MEDICINE.REC.1399.590).

\section{Consent for publication}

Not applicable

\section{Competing interests}

The authors declare that they have no competing interests.

\section{Author details}

'Department of Medical Genetics, School of Medicine, Tehran University of Medical Sciences, Tehran, Iran. ${ }^{2}$ Department of Gastroenterology, Imam Khomeini Hospital, Tehran University of Medical Sciences, Tehran, Iran. ${ }^{3}$ Department of Immunology, School of Medicine, Tehran University of Medical Sciences, Tehran, Iran. ${ }^{4}$ Medical Genetics Network (MeGeNe), Universal Scientific Education and Research Network (USERN), Tehran, Iran. ${ }^{5}$ Department of Medical Genetics, Shahid Beheshti University of Medical Sciences, Tehran, Iran. ${ }^{6}$ Department of Medical Genetics, Cancer Institute of Iran, Imam Khomeini Hospital Complex, Tehran University of Medical Sciences, Dr. Qarib St., Keshavarz Blvd, Tehran, Iran.

\section{Received: 4 August 2021 Accepted: 26 August 2021}

\section{Published online: 03 September 2021}

\section{References}

1. Gustavsson B, Carlsson G, Machover D, Petrelli N, Roth A, Schmoll HJ, et al. A review of the evolution of systemic chemotherapy in the management of colorectal cancer. Clin Colorectal Cancer. 2015;14(1):1-10. PubMed PMID: 25579803. Epub 2015/01/13. eng. https://doi.org/10.1016/j.clcc.2014.11.002.

2. Kuipers EJ, Grady WM, Lieberman D, Seufferlein T, Sung JJ, Boelens PG, et al. Colorectal cancer. Nat Rev Dis Primers. 2015;1(1):15065. PubMed PMID: 2789416. Pubmed Central PMCID: Pmc4874655. Epub 2015/01/01. eng,. https://doi.org/10.1038/nrdp.2015.65.

3. Cho YA, Lee J, Oh JH, Chang HJ, Sohn DK, Shin A, et al. Genetic risk score, combined lifestyle factors and risk of colorectal cancer. Cancer Res Treat. 2019;51(3):1033-40 PubMed PMID: 30336659. Epub 10/18. eng.

4. Dolatkhah R, Somi MH, Kermani IA, Ghojazadeh M, Jafarabadi MA, Farassati $F$, et al. Increased colorectal cancer incidence in Iran: a systematic review and meta-analysis. BMC public health. 2015;15(1):1-14.

5. Testa U, Pelosi E, Castelli G. Colorectal cancer: genetic abnormalities, tumor progression, tumor heterogeneity, clonal evolution and tumor-initiating cells. Med Sci (Basel). 2018;6(2):31 PubMed PMID: 29652830. eng.

6. Lizarbe MA, Calle-Espinosa J, Fernández-Lizarbe E, Fernández-Lizarbe S, Robles MÁ, Olmo N, et al. Colorectal cancer: from the genetic model to posttranscriptional regulation by noncoding RNAs. Biomed Res Int. 2017; 2017:7354260 PubMed PMID: 28573140. Epub 05/10. eng.

7. Okugawa Y, Grady WM, Goel A. Epigenetic alterations in colorectal cancer: emerging biomarkers. Gastroenterology. 2015;149(5):1204-25.e12 PubMed PMID: 26216839. Epub 07/26. eng.

8. Gao M, Guo Y, Xiao Y, Shang X. Comprehensive analyses of correlation and survival reveal informative IncRNA prognostic signatures in colon cancer. World J Surg Oncol. 2021;19(1):1-15.

9. Qu Y, Chen Y, Zhang L, Tian L. Construction of prognostic predictor by comprehensive analyzing alternative splicing events for colon adenocarcinoma. World J Surg Oncol. 2020;18(1):1-12.

10. Fang $Z, X u S$, Xie $Y$, Yan W. Identification of a prognostic gene signature of colon cancer using integrated bioinformatics analysis. World J Surg Oncol. 2021;19(1):1-14.

11. Fan X, Liu L, Shi Y, Guo F, Wang H, Zhao X, et al. Integrated analysis of RNAbinding proteins in human colorectal cancer. World J Surg Oncol. 2020; 18(1):222. PubMed PMID: 32828126. Pubmed Central PMCID: PMC7443297. Epub 2020/08/24. eng. https://doi.org/10.1186/s12957-020-01995-5.
12. Xia Z, Wang C, Zhang $H$. The downregulation of NCXs is positively correlated with the prognosis of stage II-IV colon cancer. World J Surg Oncol. 2021;19(1):1-14

13. Wang $Y, H-b$ X, Z-m C, Meng $L, A-m X$. Identification of a ferroptosis-related gene signature predictive model in colon cancer. World J Surg Oncol. 2021; 19(1):1-12.

14. Chu S, Wang H, Yu M. A putative molecular network associated with colon cancer metastasis constructed from microarray data. World J Surg Oncol. 2017;15(1):1-9.

15. Rajappa A, Banerjee S, Sharma V, Khandelia P. Circular RNAs: emerging role in cancer diagnostics and therapeutics. Front Mol Biosci. 2020;7:577938 PubMed PMID: 33195421. eng.

16. Rao AKDM, Arvinden VR, Ramasamy D, Patel K, Meenakumari B, Ramanathan $P$, et al. Identification of novel dysregulated circular RNAs in early-stage breast cancer. J Cell Mol Med. 2021;25(8):3912-21 PubMed PMID: 33544410. Epub 02/05. eng.

17. Holdt LM, Kohlmaier A, Teupser D. Molecular roles and function of circular RNAs in eukaryotic cells. Cell Mol Life Sci. 2018;75(6):1071-98 PubMed PMID: 29116363. Epub 11/07. eng.

18. Szabo L, Morey R, Palpant NJ, Wang PL, Afari N, Jiang C, et al. Statistically based splicing detection reveals neural enrichment and tissue-specific induction of circular RNA during human fetal development. Genome Biol. 2015;16(1):126 PubMed PMID: 26076956. eng.

19. Gao C, Zhang Y, Tian Y, Han C, Wang L, Ding B, et al. Circ_0055625 knockdown inhibits tumorigenesis and improves radiosensitivity by regulating miR-338-3p/MSI1 axis in colon cancer. World J Surg Oncol. 2021; 19(1):1-13.

20. Zhang W, Dahlberg JE, Tam W. MicroRNAs in tumorigenesis: a primer. Am J Pathol. 2007;171(3):728-38 PubMed PMID: 17724137. eng.

21. Wang Y, Luo J, Zhang H, Lu J. microRNAs in the same clusters evolve to coordinately regulate functionally related genes. Mol Biol Evol. 2016;33(9): 2232-47 PubMed PMID: 27189568. Epub 04/28. eng.

22. Cekaite L, Eide PW, Lind GE, Skotheim RI, Lothe RA. MicroRNAs as growth regulators, their function and biomarker status in colorectal cancer. Oncotarget. 2016;7(6):6476-505. PubMed PMID: 26623728. Pubmed Central PMCID: Pmc4872728. Epub 2015/12/02. eng. https://doi.org/10.18632/ oncotarget.6390.

23. Wang H, Lapek J, Fujimura K, Strnadel J, Liu B, Gonzalez DJ, et al. Pseudopodium-enriched atypical kinase 1 mediates angiogenesis by modulating GATA2-dependent VEGFR2 transcription. Cell Discov. 2018;4(1): $1-24$.

24. Liu M, Liu K, Zhang L, Cai J, Yao H, Bai Y, et al. Circ_0009910 regulates growth and metastasis and is associated with poor prognosis in gastric cancer. Eur Rev Med Pharmacol Sci. 2018;22(23):8248-56. https://doi.org/1 0.26355/eurrev_201812_16519.

25. Kadkhoda S, Darbeheshti F, Rezaei N, Azizi-Tabesh G, Zolfaghari F, Tavakolibazaz S, et al. Investigation of circRNA-miRNA-mRNA network in colorectal cancer using an integrative bioinformatics approach. Gastroenterol Hepatol Bed Bench. 2021;14(2):141-53 PubMed PMID: 33968341. eng.

26. Chan JJ, Tay Y. Noncoding RNA: RNA regulatory networks in cancer. Int J Mol Sci. 2018;19(5):1310 PubMed PMID: 29702599. eng.

27. Sawicki T, Ruszkowska M, Danielewicz A, Niedźwiedzka E, Arłukowicz T, Przybyłowicz KE. A Review of colorectal cancer in terms of epidemiology, risk factors, development, symptoms and diagnosis. Cancers (Basel). 2021; 13(9):2025 PubMed PMID: 33922197. eng.

28. Weng W, Wei Q, Toden S, Yoshida K, Nagasaka T, Fujiwara T, et al. Circular RNA ciRS-7-A promising prognostic biomarker and a potential therapeutic target in colorectal cancer. Clin Cancer Res. 2017;23(14):3918-28. PubMed PMID: 28174233. Pubmed Central PMCID: Pmc5511556. Epub 2017/02/09. eng. https://doi.org/10.1158/1078-0432.CCR-16-2541.

29. Li X, Wang J, Zhang C, Lin C, Zhang J, Zhang W, et al. Circular RNA circlTGA7 inhibits colorectal cancer growth and metastasis by modulating the Ras pathway and upregulating transcription of its host gene ITGA7. J Pathol. 2018;246(2):166-79. PubMed PMID: 29943828. Epub 2018/06/27. eng. https://doi.org/10.1002/path.5125.

30. Zhang Q, Zhang C, Ma JX, Ren H, Sun Y, Xu JZ. Circular RNA PIP5K1A promotes colon cancer development through inhibiting miR-1273a. World J Gastroenterol. 2019;25(35):5300-9. PubMed PMID: 31558874. Pubmed Central PMCID: PMC6761237. Epub 2019/09/29. eng. https://doi.org/10.374 8/wjg.v25.i35.5300. 
31. An J, Chen Z, Ma Q, Li Y, Shi F. Liraglutide improves atherosclerosis by regulating long non-coding RNA RMRP/miR-128-1-5P/Gadd45g axis. Eur Rev Med Pharmacol Sci. 2020;24(5):2725-37. https://doi.org/10.26355/eurrev_202 003_20545.

32. Zhang Y, Li C, Liu X, Wang Y, Zhao R, Yang Y, et al. circHIPK3 promotes oxaliplatin-resistance in colorectal cancer through autophagy by sponging miR-637. EBioMedicine. 2019;48:277-88. PubMed PMID: 31631038. Pubmed Central PMCID: Pmc6838436. Epub 2019/10/22. eng. https://doi.org/10.1016/ j.ebiom.2019.09.051.

33. Li Y, Lin S, An N. Hsa_circ_0009910: oncogenic circular RNA targets microRNA-145 in ovarian cancer cells. Cell Cycle. 2020;19(15):1857-68 PubMed PMID: 32588730

34. Li HW, Liu J. Circ_0009910 promotes proliferation and metastasis of hepatocellular carcinoma cells through miR-335-5p/ROCK1 axis. Eur Rev Med Pharmacol Sci. 2020;24(4):1725-35. PubMed PMID: 32141540. Epub 2020/03/07. eng. https://doi.org/10.26355/eurrev_202002_20349.

35. Cao HX, Miao CF, Sang LN, Huang YM, Zhang R, Sun L, et al. Circ_0009910 promotes imatinib resistance through ULK1-induced autophagy by sponging miR-34a-5p in chronic myeloid leukemia. Life sciences. 2020;243: 117255. PubMed PMID: 31923418. Epub 2020/01/11. eng. https://doi.org/1 0.1016/j.lfs.2020.117255.

36. Ping L, Jian-Jun C, Chu-Shu L, Guang-Hua L, Ming Z. Silencing of circ_ 0009910 inhibits acute myeloid leukemia cell growth through increasing miR-20a-5p. Blood Cells Mol Dis. 2019;75:41-7. PubMed PMID: 30612066. Epub 2019/01/07. eng. https://doi.org/10.1016/j.bcmd.2018.12.006.

37. Deng N, Li L, Gao J, Zhou J, Wang Y, Wang C, et al. Hsa_circ_0009910 promotes carcinogenesis by promoting the expression of miR-449a target IL6R in osteosarcoma. Biochem Biophys Res Commun. 2018:495(1):189-96. PubMed PMID: 29117539. Epub 2017/11/09. eng. https://doi.org/10.1016/j. bbrc.2017.11.028.

38. Feng Y, Zhu J, Ou C, Deng Z, Chen M, Huang W, et al. MicroRNA-145 inhibits tumour growth and metastasis in colorectal cancer by targeting fascin-1. Br J Cancer. 2014;1 10(9):2300-9. PubMed PMID: 24642628. Pubmed Central PMCID: Pmc4007224. Epub 2014/03/20. eng. https://doi.org/10.1038/ bjc.2014.122.

39. Wang Y, Dan L, Li Q, Li L, Zhong L, Shao B, et al. ZMYND10, an epigenetically regulated tumor suppressor, exerts tumor-suppressive functions via miR145-5p/NEDD9 axis in breast cancer. Clin Epigenetics. 2019; 11(1):184 PubMed PMID: 31801619

40. Guo Q, Qin W, Li B, Yang H, Guan J, Liu Z, et al. Analysis of a cytoskeletonassociated kinase PEAK1 and E-cadherin in gastric cancer. Pathol Res Pract. 2014;210(12):793-8. PubMed PMID: 25445115. Epub 2014/12/03. eng. https://doi.org/10.1016/j.prp.2014.09.013.

41. Ding $\mathrm{C}$, Tang $\mathrm{W}$, Fan $\mathrm{X}$, Wang $\mathrm{X}, \mathrm{Wu} \mathrm{H}, \mathrm{Xu} \mathrm{H}$, et al. Overexpression of PEAK1 contributes to epithelial-mesenchymal transition and tumor metastasis in lung cancer through modulating ERK1/2 and JAK2 signaling. Cell Death Dis. 2018;9(8):802. PubMed PMID: 30038287. Pubmed Central PMCID: Pmc6056550. Epub 2018/07/25. eng. https://doi.org/10.1038/s41419-018-081 7-1.

42. Ding C, Tang W, Wu H, Fan X, Luo J, Feng J, et al. The PEAK1-PPP1R12B axis inhibits tumor growth and metastasis by regulating Grb2/PI3K/Akt signalling in colorectal cancer. Cancer Lett. 2019:442:383-95. PubMed PMID: 30472186. Epub 2018/11/26. eng. https://doi.org/10.1016/j.canlet.2018.11.014.

43. Huang L, Wen C, Yang X, Lou Q, Wang X, Che J, et al. PEAK1, acting as a tumor promoter in colorectal cancer, is regulated by the EGFR/KRas signaling axis and miR-181d. Cell Death Dis. 2018;9(3):271. PubMed PMID: 29449544. Pubmed Central PMCID: Pmc5833579. Epub 2018/02/17. eng. https://doi.org/10.1038/s41419-018-0320-8.

\section{Publisher's Note}

Springer Nature remains neutral with regard to jurisdictional claims in published maps and institutional affiliations.

Ready to submit your research? Choose BMC and benefit from:

- fast, convenient online submission

- thorough peer review by experienced researchers in your field

- rapid publication on acceptance

- support for research data, including large and complex data types

- gold Open Access which fosters wider collaboration and increased citations

- maximum visibility for your research: over $100 \mathrm{M}$ website views per year

At BMC, research is always in progress.

Learn more biomedcentral.com/submissions 